\title{
POSSIBILITIES OF NANODIAMONDS APPLICATION - BIOLOGICAL AND MEDICAL ASPECTS
}

\author{
KATARZYNA SOLARSKA-ŚCIUK* and HALINA KLESZCZYŃSKA
}

\author{
Department of Physics and Biophysics, \\ Wroclaw University of Environmental and Life Sciences, \\ Norwida 25, 50-375 Wrocław, Poland
}

\begin{abstract}
This topical review briefly discusses selected highlights of research on diamond nanoparticles obtained by different methods and their potential applications in biology and medicine. In recent years nanotechnology has aroused interest of a large number of scientists who endeavor to obtain nanoparticles (which differ in size and structure of surface) using different methods, in order to determine their physical, chemical and biological properties that are in relation to the methods used in the process of their production. The knowledge developed in this way will be beneficial in an attempt to use nanoparticles more reasonably in various branches of science. The distinguishing features of carbon nanoparticles are their biocompatibility, photostability and easily chemically modified surface that results in high usefulness for intracellular studies. What is more, low toxicity of nanoparticles with many cell lines is at the center of scientific interest. This, in turn, leads to a large number of biomedical applications. The property that nanodiamonds are able to penetrate cells through endocytosis, allows delivering the drug connected with nanoparticles into cancer cells. These features of nanoparticles have given many promising leads in nanooncology, in particular in drug delivery, diagnosis, imaging, and therapy. This paper presents a summary of different classes of nanodiamond particles, the ways of their uptake into cells, an overview of the possible application of nanoparticles as nanocarriers and as a clinical theranostic platform, as well as advantages and disadvantages of using nanodiamonds in biomedicine.
\end{abstract}

Keywords: diamond nanoparticles, surface functionalization, biocompatibility, endocytosis, drug transporters

In recent years, the development of nanoscience and nanotechnology has been observed. A broad scope of nanomaterials has been synthesized and discovered. Furthermore, due to properties and potential applications, a number of carbon nanoparticles have been receiving significant attention (1, 2). Carbon is a commonly occurring element on the Earth, the element of life, and also becomes an element of progress. Atomic carbon is a very shortlived species, but it is stabilized in various multiatomic structures in different molecular configurations called allotropes. There is a well-known variety of allotropic forms of carbon such as diamond, graphite, fullerenes, graphene, nanotubes. Nanodiamonds are, however, the most common. All the above-mentioned varieties are receiving much attention due to their remarkable mechanical, electrical, and thermal properties. Differences between varieties allotropic forms relate to their structure which has been used to create unique devices at the nanoscale level that possess novel chemical and physical functional properties $(3,4)$.

In addition, the genesis of nano- and micronsized diamond in nature is also important. It is worth mentioning that on the basis of geological, mineralogical, geochemical as well as experimental data it is possible to distinguish four main groups of natural diamonds. Every type of natural diamonds have its properties: the first type comprises interstellar nandnodiamod particles, the second includes crustal micron- and nanometer scale diamonds associated with coals, sediments and metamorphic rocks, the third includes nanodiamonds and micron diamonds associated with secondary (hydrothermal) alteration and replacing reactions in mafic rocks, and the fourth group includes macro-, micron- and nanosized mantle diamonds which are associated with kimberlites, mantle peridotite and eclogites. Studies regarding diamonds in different scientific domains have been widely conducted in geochemistry and

\footnotetext{
* Corresponding author: e-mail: solarskakatarzyna.biol@gmail.com
} 
astrophysics in order to discover novel methods of diamond nanoparticles synthesis and to develop useful applications (5).

Diamond nanoparticles are obtained using various methods which are expected to affect their properties, including biocompatibility. In 1962, Danilenko proposed and implemented ampoule-free synthesis with explosions in an explosion chamber, instead of ampoule synthesis in the ultradispersed detonation diamond (UDD) method $(6,7)$. The final products of detonation are nanodiamond particles of average size between $4-5 \mathrm{~nm}$ and other graphitic carbon forms. Therefore, in order to purify the particle surface from other functional groups, rigorous cleaning stages are then employed. The method of cleaning depends on the source of the ND powder. Diamond nanoparticles can form aggregates of up to $20 \mathrm{~nm}$. It is observed that commercial detonation nanoparticles contain up to $98 \%$ diamond in the form of 2-10 nm particles with extremely small amounts of $\mathrm{sp}^{2}$ impurity $(8,9)$.

Other methods used to synthesize carbon nanoparticles is MW/RF PACVD (microwave and radio frequency plasma-assisted chemical vapur deposition) and RF PACVD (radio frequency plasma-activated chemical vapur deposition method). MW/RF PACVD method connects the advantages of microwave discharge (high concentration of ions and active species) with the ability to control ion energy by using negative bias. For this synthesis, either pure methane $\left(\mathrm{CH}_{4}\right)$ or its mixture with such gases as nitrogen $\left(\mathrm{N}_{2}\right)$, argon $(\mathrm{Ar})$, and oxygen $\left(\mathrm{O}_{2}\right)$ are used and methane is introduced into the reactor at a flow rate of 90-100 sccm. Methane, as a source of carbon, is supplied through the quartz tubing before the deposition, the chamber is evacuated to the pressure of $100 \mathrm{~Pa}$. During the process the parameters are controlled, including total pressure, gas flow rates, MW and RF power supplied, and reflected. The parameters of the deposition are optimized to get nanodiamond particles of grain sizes above $10 \mathrm{~nm}$ (10). RF PACVD method is based on plasma excitation in methane with nitrogen and other hydrocarbons in an RF electric field under reduced gas pressure of hundreds $\mathrm{Pa}(11,12)$.

In addition, excellent optical and mechanical properties and a high degree of biocompatibility indicate that diamond nanoparticles are perfect materials for biomedical applications. Furthermore, in bioimaging and biosensing applications, $\mathrm{NV}^{-}$ doped NDs have been proposed as optical probes. That is way the efficient synthesis of nanodiamonds with controlled size distribution and concentration of $\mathrm{NV}^{-}$centers is of high importance for the development of a wide range of applications.
Nanodiamonds embedded in the diamondlike carbon films were obtained by the Pulsed Lased Deposition (PLD).This is the process in which the pyrolytic graphite target is mounted inside a vacuum chamber, where it is irradiated with a $\mathrm{KrF}$ excimer laser. The laser beam impinges on the pyrolytic graphite. In another step, the ablation process of the target is performed either in a vacuum or controlled $\mathrm{N}_{2}$ atmosphere and the ablated material gets deposited onto a silicon substrate. After that, the discussed process is continued by a cleaning procedure of the silicon substrates (includes three subsequent baths in ultrapure acetone, ethanol and deionized water in an ultrasonic bath and then dried with gaseous nitrogen flux). During deposition, the temperature of the material is kept at $\sim 100^{\circ} \mathrm{C}$. Then the thin film is annealed at $300^{\circ} \mathrm{C} / 1 \mathrm{~h}$ (in order to reduce the internal stress and avoid delamination) when the high amount of $\mathrm{sp}^{3}$ carbon atoms is formed (13).

Endothelial cells play a crucial role in physiology of the cardiovascular system, forming a thin layer on the inner surface of blood vessels that provides an anticoagulant barrier between the vessel wall and blood. Another extremely important function of the cells is a significant paracrine and endocrine activity. They also can be activated by various stimuli and play a role in angiogenesis and vasculogenesis. For that reason, a wide spectrum of studies is focused on comparing the biocompatibility of several types of carbon nanoparticles (obtained by various methods) on the basis of their interaction with human endothelial cells (14-16). The results showed that the biocompatibility of nanodiamonds depends on their properties and the method of synthesis. Furthermore, the content of diamond phases is the basic difference between the nanoparticles obtained by the detonation and RF/PACVD and MW/RF PACVD methods. As a result of that, nanoparticles manufactured using the microwave and radio frequency plasma-assisted chemical vapur deposition and radio frequency plasma-activated chemical vapur deposition methods showed a lower level of cytotoxicity than nanodiamonds obtained by detonation method which showed a stronger biological activity (14). This is the main reason for explaining why diamond nanoparticles manufactured by detonation method are extremely interesting. The detonation nanodiamonds have the smallest particle sizes among particulate synthetic diamonds, with size ranging from 4 to $5 \mathrm{~nm}$ and the tendency to aggregate is observed via interparticle bonding. The dispersal of detonation diamond particles can be changed e.g. by way of ultrasonic treatment. The observation that core agglomerates are 
not affected by that treatment is important due to the fact that core agglomerates are strongly bound by graphitic soot-like structures (17-19). The nanodiamond surface, after being detonated, is covered with a variety of functional groups: hydrogen, hydroxyl groups or other chemical groups including e.g. carboxylic acids, esters, ethers, lactones, amines, and structural elements i.e. carbon black $\mathrm{sp}^{2}$ which show tendency to agglomerate (20-23).

In particular, the nanoparticles obtained in the process of detonation tend to form loosely or tightly clustered aggregates of size from 200 to $400 \mathrm{~nm}$. The formation of these aggregated nanoparticles can exert an effect on changes in their surface, energy and the final use of application. On the other hand, nanoparticles obtained by HPHT (High Pressure, High Temperature) and CVD (Chemical Vapor Deposition) methods show only a moderate tendency to agglomerate (Table 1).

While all of the above examples of diamond synthesis are interesting, this paper focuses on the properties and applications of nanodiamond particles formed through detonation (commonly described as detonation ND or ultradispersed diamond or nanocrystalline diamond) as a result of the fact that the detonation synthesis remains a primary source of ND particles in the process of production that has the widest use in various applications $(24,25)$. Easy access to nanodiamonds plays a fundamental role in the research conducted by a wide range of scientists who endeavor to obtain new nanoparticles and extend the scope for their applications. The mentioned above process is possible after earlier surface modification. As a result of this, the physicochemical properties of the nanoparticles are changed and functional groups can be replaced by other groups $(21,26,27)$. Surface modification of ND allows radical surface functionalization. As a result of this process, the characteristics of diamond nanoparticles can be distinguished in comparison to the other nanoparticles and exhibit high surface reactivity compared to other carbon nanostructures. Many

Table 1. Summary of the strategies for the synthesis of nanodiamonds.

\begin{tabular}{|c|c|c|c|c|}
\hline Synthesis technique & Average size & Advantages & Limitations & Ref. \\
\hline $\begin{array}{c}\text { Ultradispersed } \\
\text { detonation diamond } \\
\text { (UDD) }\end{array}$ & $2-5 \mathrm{~nm}$ & $\begin{array}{c}\text { Industrial scale production } \\
\text { A wide range of } \\
\text { possibilities diamond } \\
\text { nanoparticles surface } \\
\text { modifications }\end{array}$ & $\begin{array}{l}\text { Diamond nanoparticles can } \\
\text { form aggregates of up } \\
\text { to } 20 \text { nm Expensive production } \\
\text { Different steps of } \\
\text { purification are necessary }\end{array}$ & $(6-9)$ \\
\hline $\begin{array}{l}\text { Chemical } \\
\text { vapor deposition } \\
\text { (CVD) }\end{array}$ & $5-100 \mathrm{~nm}$ & $\begin{array}{l}\text { Useful for } \\
\text { fabricating } \\
\text { films }\end{array}$ & $\begin{array}{l}\text { Strategy limited to the } \\
\text { production of films. } \\
\text { Expensive production }\end{array}$ & $(24,25)$ \\
\hline $\begin{array}{l}\text { High-pressure and } \\
\text { high temperature } \\
\text { (HPHT) }\end{array}$ & $>20 \mathrm{~nm}$ & $\begin{array}{l}\text { Higher nitrogen content } \\
\text { useful for imaging } \\
\text { applications }\end{array}$ & Expensive production & $(24,25)$ \\
\hline $\begin{array}{l}\text { Microwave and Radio } \\
\text { Frequency Plasma } \\
\text { Assisted Chemical } \\
\text { Vapour Deposition } \\
\text { (MW/RF PACVD) }\end{array}$ & $150-200 \mathrm{~nm}$ & $\begin{array}{l}\text { Very promising due to } \\
\text { their low cytotoxicity } \\
\text { for cells }\end{array}$ & $\begin{array}{l}\text { Show properties to } \\
\text { aggregate } \\
\text { High production costs }\end{array}$ & $(10-12)$ \\
\hline $\begin{array}{l}\text { Radio Frequency } \\
\text { Plasma Activated } \\
\text { Chemical Vapour } \\
\text { Deposition } \\
\text { (RF PACVD) }\end{array}$ & $500-800 \mathrm{~nm}$ & $\begin{array}{l}\text { Very promising due to } \\
\text { their low cytotoxicity } \\
\text { for cells }\end{array}$ & $\begin{array}{l}\text { Show properties to } \\
\text { aggregate } \\
\text { Expensive production }\end{array}$ & $(10-12)$ \\
\hline $\begin{array}{l}\mathrm{NV}^{-} \text {doped } \\
\text { fluorescent } \\
\text { NDs }\end{array}$ & $10-100 \mathrm{~nm}$ & $\begin{array}{c}\text { Proposed as optical } \\
\text { probes for bioimaging } \\
\text { and biosensing applications } \\
\text { The process is easily } \\
\text { scalable, and should } \\
\text { provide a facile means } \\
\text { for the production of } \\
\mathrm{NV}^{-} \text {doped fluorescent } \\
\text { nanoparticles }\end{array}$ & Expensive production & (13) \\
\hline
\end{tabular}


procedures of nanodiamonds surface chemical functionalization are well known, but the outcome depends basically on the process of purification and consequently the level of purity and uniformity of diamond nanoparticles. The stability of nanodiamond surfaces is extremely important for functionalization, particularly with respect to drug binding ability and imaging. Owing to this potentials and capabilities, diamond nanoparticles-drug complexes that are formed either by physical adsorption or chemical conjugation have the benefit of reducing the multidrug resistance of anticancer drugs and enhancing delivery efficacy $(19,21,23,28,29)$.

There is a large number of nanoparticles, one type among them is worth noticing, namely nanogold. As it turns out, there are many methods of obtaining nanogold which size and shape are suitable for the final function/role. One of the proposed methods is the radiolytic synthesis which allows proper control of the nucleation process without reducing agents, in a single step, combined or not with simultaneous sterilization. This reaction occurs in the absence of chemical reducing agents or additional toxic compounds. On the other hand, the lack of such compounds during manufacturing contributes to the low toxicity of the final product and reduces the need for associated washing or removal stages. Freitas de Freitas et al., present the study, in which they use the radiolytic synthesis where nanoparticles synthesis and fictionalization may be carried out in a single step. Nevertheless, they comment that there are several mechanistic points to be elucidated and improvements to be done in the process of those nanomaterials on the synthesis and an application-based approach. Gold nanoparticles, similarly to nanodiamonds, have a wide spectrum of biomedical applications. They can be used as biosensors, antibacterial agents, agents for cancer imaging or as a nanotherapy agents in oncology for instance in photothermal therapy (PTT), photodynamic therapy (PDT) and theranostics $(30,31)$.

The direct coupling of drugs with gold constitutes an essential feature of the unique conjugates that creates a promising platform for applications in nanomedicine. One of the examples is the conjugate consisting of gold nanoparticles (AuNPs) and a pharmacologically active anticancer substance abiraterone $(\mathrm{AB})$ or genistein (AuNPs-GE). The obtained results suggest that the complexes AuNPs with anticancer drugs can enhance their anticancer effect $(32,33)$.

Another example of conjugates was doxorubicin (which is an effective and widely used cancer chemotherapeutic agent). Du et al. designed a gold nanoparticle-based drug delivery system where they tested five novel thiolated doxorubicin analogs were synthesized and their biological activities evaluated. The results showed that the release of the native drug can be achieved by the action of reducing agents such as glutathione or under acidic conditions, but that reductive drug release gave the cleanest drug release. The final effect was extremely promising because treatment of mice with nanogoldDox gave no histopathologically observable differences from mice treated with saline, while mice treated with an equivalent dose of doxorubicin showed significant histopathologically observable lesions (34). Regarding the safety of gold nanoparticles, extremely important is their size, concentration and time of exposure. The nanoparticles might seem safe for short-term uses. Moreover, their accumulation in long-term exposures might lead to toxic effects, that is why more and more experiment both in vitro and in vivo is required (30).

A wide spectrum of information is collected regarding other examples of nanoparticles and their applications. It is difficult to select only one the most promising nanoparticle because each of them has some characteristic features, applications and a broad scope of advantages and disadvantages. Therefore, it is absolutely crucial to select specific nanoparticles in a concrete situation.

In this review, the versatile chemical modifications of diamond nanoparticles, which are required to develop their desirable properties, potential nanodiamonds as a drug delivery carrier platform, and the ways to obtain different molecules e.g. genes, fluorescent markers, antibodies and proteins within cells in vitro and for other in vivo applications are summarized.

\section{Chemical modification of carbon nanoparticles}

In view of the variety of methods used to synthesize and purify the particle surface of diamond, it should be noticed that the synthesized nanoparticles have a different composition of the surface groups. For this reason, before using nanodiamond particles in search for their effects on biological systems exact characteristics of them should be obtained because even those commercially available are different $(35,36)$. Carbon nanoparticles obtained by detonation are surrounded by a layer created from partially oxidized graphite or amorphous carbon that contains various kinds of impurities (35). It is estimated that nearly half of all the atoms in these nanoparticles are on the surface. That enables the process of adsorption of atoms, molecules and other functional groups to become connected sponta- 
neously or via covalent bonds. And this affects the physical and chemical properties of nanodiamonds (37).

\section{Purification of nanodiamonds}

Purification of diamond nanoparticles is required for modern applications, especially for biomedical use. Therefore, the surface of particles obtained by the detonation method is purified by using oxidants which remove the carbon $\mathrm{sp}^{2}$ and metallic contaminants from the catalyst explosive, from a detonator and the electrode material or the process chamber. For this purpose, a mixture of acids at appropriate concentrations with additives for active oxidation, and elevated temperature is used. This process enables the formation of $\mathrm{C}-\mathrm{H}$ bonds on the diamond surface to which it is possible to attach more organic groups (36-39].

The next widely used method of purifying is high-temperature oxidation in the air, which is the oxidation and removal of amorphous carbon and graphite, as well as any metallic impurities from the surface of the nanoparticles. The treatment is conducted at a temperature of $400-430^{\circ} \mathrm{C}$ and allows, first of all, to remove the phase $\mathrm{sp}^{2}$ but not $\mathrm{sp}^{3}$ (which after purification amounts to approx. 96\%). Studies using the transmission electron microscopy and Fourier transform infrared spectroscopy show highly purified 5-nm nanoparticles covered by oxygen-containing surface functional groups $(40,41)$.

Another method of purification is to treat diamond particles with ozone at an elevated temperature that causes oxidation of the graphite phase to $\mathrm{CO}_{2}$ or CO. It is a highly effective method of purification and environmentally friendly thanks to a gas phase treatment using ozone at elevated temperatures which allows eliminating using corrosive liquid oxidizers (42).

The changes in the structure of the surface of the nanoparticles after the process of purification (both single particles and aggregates thereof) are observed and analyzed using the methods of infrared spectroscopy (FT-IR), atomic force microscopy (AFM) and X-ray crystallography (XRD). The use of proper methods of purification allows conducting functionalization of nanoparticles (by increasing the efficiency of subsequent reactions).

\section{Surface functionalization of nanoparticles}

Nanodiamonds, due to their characteristic structure that includes a core formed by carbon atom in the tetrahedral coordination $\mathrm{sp}^{3}$ ) and their chemical activity represents a new class of carbon nanomaterials susceptible to numerous chemical modifi- cations (43). Modification of the surface of nanoparticles by hydroxyl groups is the most useful method of functionalization. Scientists from many research centers strive to create on the surface of diamond nanoparticles not only hydroxyl groups (which constitute an ideal place to join another group), alkyl and aryl $(23,35,44)$ but also carboxyl groups, thereby creating more possibilities for new modifications (40, 44, 45).

The carbon atom of the carboxyl group is combined with the core of a nanodiamond by a single covalent bond (23). Such a modification is possible by using oxidizing mineral acid at a ratio of $3: 1$ $\left(\mathrm{H}_{2} \mathrm{SO}_{4}, \mathrm{HNO}_{3}\right)(46)$ or a mixture containing equal amounts of concentrated sulfuric acid, nitric acid, perchloric acid or hydrochloric acid, nitric acid and sulfuric acid (23). It is also possible to use so-called "piranha water", or a mixture of sulfuric acid and hydrogen peroxide which contributes to the creation of carboxyl groups on the surface of diamond nanoparticles (23). The success of such processes results in the removal of $\mathrm{sp}^{2}$ carbon in modified samples.This is possible due to the fact that reactivity of the disordered $\mathrm{sp}^{2}$ carbon is greater than the reactivity of $\mathrm{sp}^{3}$ carbon in a nanodiamond during oxidation. It is, therefore, concluded that the oxidation increases the phase purity of a given nanomaterial $(23,35,43)$. By connecting the amino groups to the carboxyl groups it is possible to create bonds on the surface of diamond nanoparticles that favor the formation of amides. This is possible only if the surfaces of the diamond nanoparticles are made of carboxyl groups. The reaction of $-\mathrm{NH}_{2}$ groups with $\mathrm{COOH}$ may occur after the activation of the auxiliary reagents such as N-Ethoxycarbonyl-2-ethoxy1,2-dihydroquinoline (EEDQ) or carbodiimides.

Another possibility is to start with hydrophobic carboxy-nanodiamonds by reaction with thionyl chloride and dodecylamine. As a next step, on the surface of nanoparticles, an amide bond is formed. A long hydrocarbon chain causes diamond nanoparticles to exhibit hydrophobic properties (47).

Attachment of the alkyl chains to the surface of nanodiamonds is also possible by conducting an esterification reaction of nanoparticles of diamond with carboxylic acid chlorides (40). Formation reaction of the ester bonds is possible thanks to the presence of acid chlorides and by acid catalysis (47). The resulting ester groups are weaker in comparison to the amide bonds and in the aqueous environment, they can be easily broken (48).

Other strategies of surface functionalization are the reactions using fluorine, chlorine, and hydrogen that lead to a homogeneous functionalizing dia- 
mond particle surface and its possible further modification (41). Fluorine can be attached to the surface of nanoparticles in a reaction with a gas mixture of $\mathrm{F}_{2} / \mathrm{H}_{2}$ at elevated temperatures $(35,49,50)$. Another extremely popular strategy of surface fictionalization is the creation of bonds with chlorine, possible thanks to thermal chlorination of the diamond nanoparticle molecular chlorine $\left(\mathrm{Cl}_{2}\right)$ and carbon tetrachloride $\left(\mathrm{CCl}_{4}\right)(23)$.

There is a broad scientific knowledge referring to the strategies aiming at the process of functionalization of nanodiamond powders which may lead to the formation on the surface of nanoparticles of different functional groups that can be used at the following stages of the surface modification process. The newly created organic groups can be used as a place for attachment of drugs or other biologically active molecules.

Noncovalent modifications can also be used to create the permanent joining of nanoparticles with larger biomolecules and thus facilitate their transport and also affect the solubility of highly lipophilic compounds (50-54). The drawback of this connection is that the molecules attached to the nanoparticles can lose their activity due to nonspecific binding because they are connected to the surface of nanodiamond in a random manner. On the other hand, in order to achieve success in modifying the surface, it is necessary to use selectively specific binding of molecules to the surface of nanoparticles so as to avoid inactivating of the connecting particles (which binds to the active part of nanodiamond) and to enable the best use of the surface of nanoparticles. Therefore, it is not surprising that functional groups that are present on the particle surface are prone to interparticle reactions, yielding covalently-bound agglomerates, which are even more difficult to destroy and whose particle sizes are in the range of several hundred nanometers. Surface modification of nanoparticles by functionalizing different molecules (markers) can be instrumental for their use as cellular markers or drug transporters (provided various antibiotics are attached to them) and this, in turn, increases the range of their application for diagnostic and therapeutic goals (55). Functionalized nanoparticles obtained from CVD or detonation experiments are mostly associated with the preparation of new nontoxic drug carriers and biosensors and they are key prospective organic molecules with many potential applications in biology, biomedicine, nanomaterial chemistry or nanoelectronics.

Arafnifard and Shojaei have noted that the process of nanodiamond surface functionalization is varied because basically there are many functional groups. For instance, selective air oxidation is a way to remove $\mathrm{sp}^{2}$ bonded carbon atoms from nanodiamond and to functionalize the surface with oxygencontaining groups that include carboxyl. The abovementioned authors pay attention to functionalization that primarily happens through hydrolysis of the surface anhydrides with the water present in the environment. That is why the scientists decided to check the interaction of protonated and deprotonated water and also $\left(\mathrm{H}_{2} \mathrm{O}\right)_{20}$ water cluster with the $\mathrm{C}_{35}$ octahedral nanodiamond, and the carboxylated and aminated $\mathrm{C}_{35}$, that is $\mathrm{C}_{35}(\mathrm{COOH})_{36}$ and $\mathrm{C}_{35}\left(\mathrm{NH}_{2}\right)_{36}$, through the density functional theory (DFT) study. The results have shown that the behavior of nanodiamonds and functionalized nanodiamonds in acidic and basic aqueous solutions as well as in the presence of mist or similar environments is extremely important for further studies (56).

\section{Surface functionalization of nanoparticles by $-\mathrm{OH}$ groups}

There are well-known chemical processes that result from a process in which the surface of a nanodiamond is oxidized so as to contribute to the creation of hydroxyl groups on the surface of nanoparticles. Such modifications are used to carry out the further surface modification. Wang et al. (57) present a study in which alkyl chlorides are used in the presence of sodium hydride to obtain ether linkages on the surface of nanodiamonds. Other reactions were also used, including those particularly suitable for providing better selectivity through a large number of functional group conversions known in organic chemistry. One of the most efficient and widely known methods of hydroxylation of the nanodiamonds surface is the direct creation of hydroxyl $(-\mathrm{OH})$ groups on the surface - a reaction in raw nanoparticles with the so-called Fenton reagents (well-known oxidants), which is a mixture of hydrogen peroxide and iron sulfate in strongly acidic environment (44). In this reaction, a precursor of hydroxyl radical is hydrogen peroxide.

The mechanism of the reaction catalyzed by iron ions was described by Haber and Weiss (58). The chemists observed that hydroxyl radical $(\mathrm{OH} \bullet)$ which is formed during the reaction is stronger oxidant than molecular oxygen or ozone. It has an unpaired electron which attacks the electron-rich organic groups with a view to their pairing $(44,59$, 60).

A very similar mechanism of this process is observed during Fenton's reaction with diamond nanoparticles, in which the resulting hydroxyl radical leads to partial oxidation of the diamond surface. 
Detached hydrogen from the carbon on the surface of nanodiamond initiates oxidation. After the creation of hydroxylated nanoparticles $\mathrm{D}+\mathrm{OH}$ the surface is cleaned of contaminants. The purification process of the surface from amorphous forms of carbon does not affect their crystal structure, so the modified surface of nanodiamond can be used for a variety of covalent and noncovalent interactions with the majority of functional groups $(23,44)$.

\section{Biomedical application of nanodiamonds}

Surface modification of diamond nanoparticles by using different molecules (markers) can be used as cellular markers or transporters of various chemical compounds, which may increase the range of their use for diagnostic and therapeutic applications.

The main problem in the treatment of many diseases (including cancer) is the high cytotoxicity of drugs on normal cells. This is associated with the unfavorable biodistribution of drug or lack of its effective effects on diseased cells. It is also a result of the rapid metabolism of the drug and its rapid excretion from the body. Therefore, in order to increase the efficiency of drug delivery to the place of destination, to improve the pharmacological properties of transmitted compounds and to improve selectivity of their action, new ways of transporting various therapeutic compounds are being sought. Nanodiamonds can be used as intracellular carriers because they are non-toxic, biocompatible, nonimmunogenic and readily penetrate through cell membranes due to small sizes. A big advantage is that diamond nanoparticles, having a large surface area, can carry large amounts of drugs and contribute to greater drug accumulation in the cell, which means increased effectiveness and quality of treatment (61). Furthermore, the process of modifying the surface of diamond nanoparticles is conducted by adding the desired chemical functional groups to various biologically active molecules, e.g. proteins, antibodies, nucleic acids, polyethylenimine or sugars (62). Moreover, there is a possibility of a simultaneous connection between large numbers of chemically different molecules. In addition, on nanodiamond surface, it is possible to add not only chemotherapeutic agents but also molecules (specific cell markers) which are able to detect aberrant cells and allow to precisely target the biodistribution of drug connected with nanodiamonds. Biodistribution of nanoparticles attached to the drug depends on the properties of the carrier used: its charge, hydrophobicity or conformational.

It is also important to remember that the therapeutic compound interacts with nanoparticle surface in an indiscriminate manner dependent on various conditions of the medium, such as $\mathrm{pH}$ redox potential and concentration of sodium chloride. Changes in the conditions, e.g. decrease in $\mathrm{pH}$ of the tumor environment, can cause disconnection between the drug and carrier.

During the formation of diamond nanoparticles complexes with macromolecules, it is important to maintain the full biological, physical or chemical activity of the molecules which are transmitted. Research carried out by Perevedentseva et al. (52, 63 ) on nanodiamonds as a carrier of lysozyme shows that the size of nanoparticles has an impact on bactericidal activity of the attached protein. To assess the effect of the complex of lysozyme with nanodiamond, a strain of $E$. coli was used. It is observed that greater bactericidal activity of lysozyme is observed after adsorption of the protein to nanoparticles the size of 100 to $500 \mathrm{~nm}$, but in the case of small diamond nanoparticles $(5-50 \mathrm{~nm})$, a decrease in bactericidal activity of the enzyme is observed. It is a result of changes in the surface structure of nanoparticles induced by the process of their preparation. Changes in the topography of the surface of small nanoparticles (in appearance or other features) could influence the structure of lysozyme and affect its activity. Regarding bigger nanoparticles, the topography of the surface structure is more stable, and therefore, the enzyme activity is practically unchanged.

Kossovsky et al. demonstrate that the complex of nanoparticles with MAP antigen can be administered to rabbits having anti-MAP and exert an effect on a strong immune response without changes in the number of white blood cells, what is extremely important in the treatment of diseases. Therefore, nanodiamonds can be a potential antigen delivery vehicles and contribute to increased specific immune response (64).

Diamond nanoparticles, due to their biocompatibility and the large surface of the adsorbent area, are used in the transport of insulin (50). In the first step, the ability of nanodiamonds to absorb the drug on its surface by means of physical forces and its $\mathrm{pH}$ dependency is evaluated. The reverse reaction is desorption of insulin by exposure of the complex to alkaline environment mediates via interaction between the diamond nanoparticles and insulin resulting in protein release that occurs to be the most intensely alkaline in reference to $\mathrm{pH}$. After placing the complex in solutions of different $\mathrm{pH}$, the amount of released insulin is observed in line with increasing $\mathrm{pH}$ in the range of $8.90,9.35,10.35$ and 11.53 . Desorption of insulin from the complex with nanodiamond is also monitored in water. The results 
showed differences in the amount of insulin released, depending on whether the environment is alkaline or neutral. It is found that more hormones are removed from the complex under alkaline conditions. The main reason for this phenomenon is an alteration of charge, as a result of which some changes take place in the electrostatic repulsion and insulin is released. The largest quantities of the hormones were released in the first day but in the following days, the hormone was released significantly slowly. It is suggested that complex nanoparticles created with insulin can be used in wound healing. Therefore, the release of the hormone from the complex (insulin-nanodiamond) in an alkaline environment prevailing in the area of injury is fundamental for reducing infection and stimulating the healing process.

Practical usage of such a system relies on the retained function of the drug upon release from the ND surface what was presented in a study obtained by using MTT viability assays (for RAW 264.7 macrophage cells) and RT-PCR (for 3T3-L1 adipocytes). It suggests that insulin function is indeed preserved subsequently to desorption, as noted by cell viability and gene expression analysis. It was observed an increased viability levels of cells, and that the released insulin activated cellular recovery pathways following the serum-starvation period. The MTT viability assays correlated with results from gene expression studies from RT-PCR (the relative expression of genes Ins 1 and Csf3/G-csf, which are upregulated by insulin stimulation of adipocyte cells). Expression levels for samples containing insulin released increased for each gene, demonstrating the effectiveness of insulin after desorption from ND surface. To conclude, diamond nanoparticles may serve as a proficient platform for insulin delivery and are promising in a wide range of therapeutic treatments (50).

Nanodiamonds may be very promising transporter for the new generation therapeutic compounds which are used in gene therapy, in particular, when the surface of diamond nanoparticles is coated with polyethyleneimine (PEI 800) or polylysine, which provide to the surface positive charge that facilitates binding of the nucleic acid, e.g. plasmid DNA or siRNA. In that case, the nanoparticles are the carriers of genes that are transferred into eukaryotic cells by transfection. The results prove that complex of nanodiamond-PEI800 delivery of siRNA to silence GFP expression results in increased efficacy over lipofectamine (a widely used delivery platform) in physiological conditions. Also, a range of other cargos is delivered including cova- lently attached proteins, drugs or small molecules under acidic conditions (which are observed in tumors) and siRNA (for very specific cancers) (65).

In other studies, the group of scientists used hydroxylated nanodiamonds connected with thionine (dyes binding to DNA) and the location of the complex ND-thionine in the nucleus was observed, leading to excitation of a wavelength of $598 \mathrm{~nm}$ emitted red fluorescence. The results encourage this research group to connect nanoparticles with triethanolamine (tris (2-hydroxyethyl) -amine; TEA) which resulted in a new cationic complex. It also allowed using this complex as a carrier for the plasmid which contains the gene coding green fluorescent protein ( $\mathrm{pEGFP}$ ). The creation of complex NDTEA-pEGFP allowed to observe illuminating green fluorescent protein in the cell and demonstrated that the nanodiamonds can be used as genes transporters that are not toxic to cells $(59,62)$ and also confirmed that nanodiamonds could be used as carriers of genes, but with the exception of the cationic nature of the nanoparticles which gave the connection with lysine. Lysine coated nanoparticles (fND) could connect with the negatively charged nucleic acids: plasmid DNA and siRNA. A suggested model for the formation of complexes between fNDs and pDNA or siRNA takes into account the binding behavior as well as the structural peculiarities of the genetic materials themselves. In the present model, the pDNA is thought to form a spherical nanostructure with positively charged fNDs. On the other hand, in the structural configuration of linear siRNA with fNDs the first is rather complex, involving several linear siRNA sequences.

\section{Antibacterial applications of nanoparticles}

Szunerits et al. present the use of nanomaterials which show antibacterial character as well as nanostructures displaying anti-adhesive activity against biofilms. Glycan-modified nanodiamonds seem to be highly promising as useful nanostructures for combating microbial infections. The focus is put on the fact that recently nanodiamonds have been used more intensively to fight against infectious diseases and biofilm formation. Moreover, NDs have proven to be a viable alternative to common antibiotics. In particular, by modifying of nanoparticles by mannose the high potential in countering E. coli-biofilm formation is shown. Moreover, it might be expected that these nanostructures have advantages over either bactericidal or bacteriostatic therapies, because of being less prone to encourage resistant strains. What is more, it is suggested that evaluation of these structures as 
potentially anti-adhesives for countering bacterial colonization and infection in vivo is necessary to be able to value the global antibacterial properties of diamond nanoparticles (66).

\section{Application of nanoparticles for purification of proteins}

Nanodiamonds are also used for the purification of proteins such as luciferase or apoobelin (enzymes which are extracted from the culture of bacterial cells-Escherichia coli). The first step, disintegrating the bacterial cells is performed by subjecting them to ultrasound in order to release their contents, or by the second method, by extracting of the enzyme from the bacterial cells using Tris- $\mathrm{HCl}$ containing urea solution. The obtained homogenate is centrifuged to achieve the supernatant which contains the enzyme. Then, to the supernatant nanodiamonds are added. The aim of this process is to adsorb proteins on the surface of nanoparticles. Subsequent to centrifugation which allows recovering enzyme that is found in the precipitate, which in next part is washed to remove unabsorbed proteins. The final step is desorption of the enzyme (where dithiothreitol (DTT) is used as a desorbing agent). Resulted in decreasing in disulfide bonds (-SH) and releasing the protein from diamond nanoparticles $(53,67)$.

Zhang et al. present a quick method (it takes about $60 \mathrm{~min}$ ) to purify protein preparations and enzymes adsorbed on the surface of nanodiamonds without losing their activity. This method is highly effective and, as a result, no impurities are left. The most important is the fact that the absorption mechanism is based on protein molecules which could be adsorbed on the surface of nanodiamonds, which is possible by forming covalent and coordination bonds, ion-exchange and hydrophobic interactions (68).

\section{Neuroactivity of DND}

Pozdnyakova et al. present the study which proves that nanoparticles obtained by the detonation method possess neuroactive properties. The initial velocity of transporter-mediated uptake is decreased in a dose-dependent manner, and accumulation of 1$[14 \mathrm{C}]$ glutamate and $[3 \mathrm{H}] \mathrm{GABA}$ in nerve terminals is observed as well as the increase of the ambient level of these neurotransmitters. Moreover, diamond nanoparticles reduce acidification of synaptic vesicles and cause depolarization of the plasma membrane of nerve terminals. It is also observed that, despite different types of structures in their surface, the common feature of nanodiamonds (synthesized from $\beta$-alanine) is the ability to affect glutamate and GABA transport in nerve terminals, and the proton gradient of synaptic vesicles. These neuromodulatory features of pure uncoated diamond nanoparticles can be used in labeling and visualizing of processes in nerve terminals, and also in theranostics (69).

\section{The ways of uptake of diamond nanoparticles into cells}

Carbon nanoparticles of the size below $200 \mathrm{~nm}$ have the ability to enter the cells. Observation of this process is possible thanks to the properties of fluorescence or luminescence of nanoparticles. Using the appropriate wavelength excitation (when using confocal microscopy techniques) makes it possible to observe the localization of the nanodiamonds inside the cells. Moreover, using a technique of transmission electron microscopy can be carried out to observe the location of the nanoparticles which do not exhibit the optical properties. The results show that carbon nanoparticles are absorbed not only on the surface of the cell membrane but also they are able to penetrate into the cytoplasm of the cell without causing damage (61). It might suggest that the transport of nanodiamond into the cells takes place by endocytosis, nevertheless, the detailed mechanism of this process is not fully elucidated.

The process of endocytosis is very common in eukaryotic cells and involves collecting cell liquids as well as small molecules and macromolecules from the external to the interior environment. This process of the generation of endocytic carriers at the cell surface involves membrane deformation, its growth into a spherical bud and, finally, membrane scission. Two types of endocytosis can be distinguished, in which very important is the kind of material which is absorbed and size of bubbles generated. These are pinocytosis, in which the absorption of fluid and small particles which are brought into the cell by forming an invagination is observed and then suspended within small vesicles (diameter of these small bubbles is $<150 \mathrm{~nm}$ ) and phagocytosis in which the larger particles are absorbed by the bubbles ranging in size from $0.1 \mathrm{~mm}$. Moreover, pinocytosis can be divided according to the size of the created bubbles and mechanism of the endosome formation. Then, there are macropinocytosis (bubbles with a diameter of $100 \mathrm{~nm}-1 \mathrm{~mm}$ ) and micropinocytosis (vesicles smaller than $150 \mathrm{~nm}$ ). The method of stimulating pinocytosis and the same mechanism of this phenomenon allows to identifying pinocytosis liquid phase and adsorption. The process of pinocytosis liquid phase (non-specific endocytosis) may be described as follows: molecules, which are dissolved in the fluid 
surrounding a cell, make an attempt to enter into the bubble of endocytosis, but on the other hand, the process of pinocytosis of adsorption is based on the involvement of receptors (specific endocytosis, selective) macromolecules which are selectively charged from the external environment. In the process of pinocytosis, various organic and inorganic compounds that are present in the environment surrounding the cells may be collected in a spontaneous way. This is possible thanks to the mobility of the plasma membrane (endocytosis liquid phase). In contrast, pinocytosis adsorption (through the bubbles surrounded by a clathrin, caveolae or blebs "non-coated") allows for cells to selectively download from the external environment a large number of compounds, particularly macromolecules e.g. hormones, low-density lipoprotein (LDL), growth factors, particles, vitamins, cytokines, some enzymes and many others (70). Diamond nanoparticles are located in the endosomes or lysosomes. A lot of studies show that the nanoparticles of the approximate dimensions $20 \mathrm{~nm}$ can be the fastest in entering into the cell, and the slowest from these nanodiamonds are those of much larger size (approximately $200 \mathrm{~nm}$ ) (71). However, nanoparticles, which size is approximately $500 \mathrm{~nm}$ are not able to penetrate into the cell $(72,73)$. Depending on the type of nanoparticles and the cell lines used in researches, differences in the location of the nanodiamonds in the cells are observed. Some of these remain in the cytoplasm, while others are able to penetrate to the cell compartments e.g.: nucleus, mitochondria and endoplasmic reticulum. Nanodiamonds obtained in a way of chemical modification of the surface (nanoparticles with different functional groups or attached medicines) may cause a change in cell morphology. These amendments are the result of the association with the appearance of disorder in the structure of the cell membrane (the appearance of gaps in the membrane), invisibly structure of the nucleus and a multitude of numerous vacuoles forming on the cytoplasm which eventually led to the death of cells by necrosis $(72,73)$. The studies show that diamond nanoparticles which can be taken into the cell by macropinocytosis and clathrin-mediated endocytosis and endocytic diamond nanoparticles do not disturb the cellular functions. It is scientifically proven that nanodiamonds modified and non-modified are not cytotoxic for the endothelial and epithelial cells at a concentration of $50 \mathrm{mg} / \mathrm{mL}$ after $24 \mathrm{~h}$ from the moment when incubated cells are treated with nanoparticles. Furthermore, the uptake ability of diamond nanoparticles provides the means of delivery of drugs but other modifications of nanoparticles can be useful in diagnostic and therapeutic applica- tions (74). The versatility of the nanodiamond-based drug delivery platform opens up a wide possibility for future applications of nanodiamonds e.g. the addition of other similar drugs as well as active targeting components such as antibodies or peptides against tumor cell surface proteins for targeted drug release. In addition, nanodiamonds offer a very promising approach to treating a broad range of difficult cancers, in particular, chemoresistant cancer stem cells (75).

\section{Transport of anticancer drugs}

The mechanism of penetration of anticancer drugs into cells is a passive associated with the uniqueness of anatomy and physiology of tumor tissue and tumor cells. The process of tumor formation takes place in a haphazard manner. The result of this is the formation of gaps in the blood vessels ranging in size from 100 to $800 \mathrm{~nm}$ between adjacent endothelial cells, whereas in normal endothelium it amounts to $2-5 \mathrm{~nm}$. Low molecular weight drugs can freely diffuse through the vascular endothelium (of normal and neoplastic cells). In contrast, the complexes (nanoparticle-drug) cannot freely pass through the sealed structure of normal endothelial cells, but relatively easily can go into tumor cells. This ensures accumulation of the drug provided by the conjugates more efficiently than the free drug. The amount of drug accumulated in the tumor delivered by the diamond nanoparticles depends on the size, surface properties of carrier and the degree of tumor development (76).

The use of drugs connected with the nanoparticles makes it possible to accumulate a larger amount of drugs in the cells and restrict their removal from the cell by $\mathrm{ABC}$ transporters. A great deal of proteins belonging to the superfamily of proteins $A B C$ (ATP-binding cassette) is in the cell membrane. These proteins act as pumps which are used to remove various compounds from cells, including anticancer drugs. The excessiveness of these proteins in cancer cells leads to the appearance of the possibility of developing drug resistance which is a serious problem in chemotherapies treatment. The high activity of $\mathrm{ABC}$ proteins in the membranes of cancer cells leads to fast ejection of the drug from inside the cell. The consequence of this is that the drug is not able to achieve high concentration in the cell, therefore, it cannot lead to the induction of apoptosis of tumor cells $(21,73)$.

\section{The complex nanodiamond-doxorubicin (ND- DOX)}

Doxorubicin hydrochloride, broadly used as a chemotherapeutic agent is one of the first chemothe- 
rapeutics attached to the nanoparticle surface. Doxorubicin (DOX) is an antibiotic of the anthracycline antitumor and is attached to the hydrophilic groups $(-\mathrm{OH}$ and $-\mathrm{COOH})$ on the surface of nanodiamond. The cancer cells HT-29 line, mouse macrophages and neuroblastoma cells were treated by complex ND-DOX $(54,77)$. The study proves that the complex of drug with nanoparticles does not lose its activity. Furthermore, it is found that the nanoparticle can be a biocompatible carrier. An additional advantage of the described system of nanoparticle-drug is to reduce the adverse systemic effects of the drug which in the free form would have to be given in a much higher concentration. By creating nanodiamonds with a modified surface it is possible to reduce the dose of a cytostatic and reduce its side effects on normal cells. In addition, the measurable effect of the complex ND-DOX is a significant reduction in tumor size compared with the effect of the drug itself. Huang et al. (54) observed that changes in ion concentration influence the degree of absorption and release of the drug from the nanodiamond surface. High concentrations of $\mathrm{NaCl}$ is conducive to drug absorption for ND, whereas low is responsible for disconnecting the nanoparticles.

Drugs connected to nanodiamond may be used in the treatment of cancers that are observed in the phenomenon of drug resistance. It is associated with overexpression of the proteins belonging to the superfamily of $\mathrm{ABC}$ transporters. The substrate for $\mathrm{ABC}$ protein is the free drug. The main role of these proteins is to effectively eliminate this drug outside the cell, preventing effective functioning inside the cell. Diamond nanoparticles complexes with the drug are not ejected from a cell, accumulate, and can interact with the cancer cells. The study shows that the complexes of nanoparticles with doxorubicin, used on mice suffering from liver cancer and breast cancer, can inhibit the process of the leakage of the drug from the cell, reduction in tumor size and increase the induction of apoptosis compared with the effect of activities of the drug itself. Moreover, it is also observed that the complex is maintained up to 10 times longer in the circulation than the drug itself $(78,79)$.

To increase the effectiveness of the complexes (diamond nanoparticles-doxorubicin) in breast cancer cells MCF-7 resistant to doxorubicin, specifically in addition to d-alpha-tocopheryl poly(ethylene glycol), succinate (TPGS) which is an inhibitor of $\mathrm{ABC}$ transporters is used. The insertion of TPGS is responsible for decreasing in the P-glycoprotein activity, increasing in intracellular accumulation of doxorubicin and drug penetrating into the cell nucleus, and also increasing in the therapeutic efficacy of the resulting nanoparticles (80).

The complex of doxorubicin-polyglycerol-nanodiamond can stimulate glioblastoma cell immunogenicity through activation of autophagy. Li et al. have shown that nanotechnology can be applied to therapeutically modulate the glioblastoma immune microenvironment by using autophagy in the cancer cells. They describe the complex of nanodiamond with doxorubicin which induces autophagy rather than apoptosis in glioblastoma cells and stimulates this cells to emit antigens and damage-associated molecular patterns that are potent adjuvants that result in enhanced activation of dendritic cells. As the effect of this process not only autophagosome release is heightened but also efficiently attenuated dendritic cells activation stimulated by Nano-DOXtreated conditioned culture medium is observed. The complex of doxorubicin-polyglycerol-nanodiamond can stimulate glioblastoma cell immunogenicity through activation of autophagy (81).

\section{The complex of nanodiamond-paclitaxel}

The presence of functional groups on the surface of nanocarbon is possible by the ester bond with a carrier. The lung carcinoma line (A549) is treated by the complex of ND- paclitaxel. To monitor the process of penetration of this complex into cell, the confocal microscopy method is used. This complex penetrates into cells through endocytosis via clathrin. Paclitaxel is released from the surface of the nanodiamonds by hydrolysis of an ester bond through the action of intracellular esterases. Paclitaxel delivered by nanoparticle contributed inhibiting the growth of tumors in mice. In this study, mice with SCID mutation were used and characterized by the absence of an immune response. Mice were implanted with xenograft cells. The cells of line A549 were subjected to 48 hours of incubation with ND-paclitaxel complex. The final effect of a functional covalent conjugation of NDpaclitaxel showed that it can be delivered into lung carcinoma cells and preserves the anticancer activities on the induction of mitotic blockage, apoptosis and antitumorigenesis (82).

\section{The complex of nanodiamond-HCPT}

The following collection of data shows connection between nanoparticles and another chemotherapeutic agent, which is 10-hydroxycamptothecin (HCPT). The studies were carried out on A549, K562 and HeLa cells lines, to determine the cytotoxicity of nanodiamonds. It is found that diamond 
nanoparticles are nontoxic to the cell providing the examination is carried out in complete culture medium with serum. Serum proteins are adsorbed on the surface of nanoparticles and play the role of protecting cells. Moreover, experiments show that also the $\mathrm{pH}$ of the environment has an impact on the absorption rate or release of the drug from the surface of diamond nanoparticles. In an environment with a $\mathrm{pH}$ slightly basic (about 8.2) the highest level of absorbed drug to nanoparticle is observed, and decreasing the $\mathrm{pH}$ ( $\mathrm{pH}$ slightly acidic) promotes the slow release of HCPT from diamond nanoparticles. The complex is more effective than free drug in relation to HeLa cells with the damage of the cell membrane, nucleus and in which the emergence of numerous vacuoles is observed (61).

\section{The complex of nanodiamond-DNR}

In recent decades, the use of nanotechnology for drug delivery systems has grown exponentially. Diamond nanoparticles demonstrate significant potential as gene or drug delivery platforms for cancer therapy. Man et al. present synthesized nanodiamonds vectors capable of chemotherapeutic loading and delivery with applications towards chemoresistant leukemia. The complex of Daunorubicin (DNR) with diamond nanoparticles which are optimized by adjusting reaction parameters, e.g. acidity and concentration, is created. The researchers used a K562 human myelogenous leukemia cell line, with multidrug resistance conferred by incremental daunorubicin exposure, to demonstrate the efficacy enhance- ment resulting from nanodiamond-based delivery. While resistant K562 cells are able to overcome treatment from DNR alone, as compared with nonresistant K562 cells, nanoparticles are able to improve daunorubicin delivery into resistant K562 cells.

By overcoming efflux mechanisms present in this resistant leukemia line (K562), nanodiamondsenabled therapeutics demonstrate potential to improve cancer treatment efficacy, especially towards resistant strains (83) (Table 2).

\section{The molecular mechanism of ND and drugs inter- action with cancer cells}

Nanodiamonds are broadly used in biomedical science and biotechnologies. These nanomaterials which present excellent biocompatibility are able to serve as versatile platforms that can be embedded within polymer-based microfilm devices. Diamond nanoparticles can be also complexed with chemotherapeutics. That enables sustained and slow release of the drug for a minimum of one month (with a significant amount of drug in reserve). This marks a new way of the potential possibilities for localized drug release as a complementary and potent form of treatment with systemic injection towards the reduction of continuous dosing and attenuation of the effects of chemotherapy. Rej et al. developed tiny synthetic diamonds that can aid in the fight against cancer by lighting up areas of cancer in MRI scans. This new technique may be used in detecting cancers that are difficult to find early

Table 2. Antitumor applications of NDs in drug delivery.

\begin{tabular}{|c|c|c|c|}
\hline Nanoparticle & Outcome & Cell lines & Ref. \\
\hline $\begin{array}{l}\text { Nanodiamond-doxorubicin } \\
\text { (ND-DOX) }\end{array}$ & $\begin{array}{l}\text { As a result of using the complex } \\
\text { ND-DOX a significant } \\
\text { reduction in tumor size } \\
\text { compared with the effect of the } \\
\text { drug itself is observed }\end{array}$ & $\begin{array}{l}\text { Cancer cells HT-29 line, } \\
\text { mouse macrophages and } \\
\text { neuroblastoma cells }\end{array}$ & $(80,81)$ \\
\hline $\begin{array}{l}\text { Nanodiamond-paclitaxel } \\
\text { (ND- paclitaxel) }\end{array}$ & $\begin{array}{l}\text { The complex ND-paclitaxel } \\
\text { showed that it can be delivered } \\
\text { into lung carcinoma cells and } \\
\text { preserves the anticancer } \\
\text { activities on the induction of } \\
\text { mitotic blockage, apoptosis and } \\
\text { antitumorigenesis }\end{array}$ & $\begin{array}{l}\text { Lung carcinoma } \\
\text { cell line } \\
\text { (A549) }\end{array}$ & (82) \\
\hline $\begin{array}{l}\text { 10-hydroxycamptothecin - } \\
\text { nanodiamond } \\
\text { (nanodiamond-HCPT) }\end{array}$ & $\begin{array}{l}\text { The complex is more effective than } \\
\text { free drug in relation to HeLa cells } \\
\text { with the serious damage in cells }\end{array}$ & $\begin{array}{l}\text { A549, K562 } \\
\text { and HeLa } \\
\text { cells lines }\end{array}$ & (61) \\
\hline $\begin{array}{c}\text { Daunorubicin - } \\
\text { nanodiamond } \\
\text { (nanodiamond-DNR) }\end{array}$ & $\begin{array}{l}\text { Nanoparticles are able to } \\
\text { improve daunorubicin delivery } \\
\text { into resistant K562 cells }\end{array}$ & $\begin{array}{l}\text { K562 (human } \\
\text { myelogenous leukemia) } \\
\text { cell line }\end{array}$ & (83) \\
\hline
\end{tabular}


on, like brain and pancreatic cancers. In this study, the team of researchers proves that nanoparticles can penetrate cell walls without damaging them, thus acting as potential drug delivery carriers during chemotherapy, especially nanodiamonds which are largely nontoxic and nonreactive (84).

Well known is also the fact that chemoresistance (which is the ability of cancer cells to escape chemotherapy treatment), is a primary cause of treatment failure in cancer. Cancer stem cells which initiate the formation of tumors are commonly found to be more resistant to chemotherapy than the rest of the bulk tumor. That can lead to cancer recurrence following chemotherapy treatment. That is the justification of the fact that a large number of scientists work with an intention to develop new drugs or treatment strategies that overcome chemoresistance, particularly in cancer stem cells. Wang et al. present the study in which the complex nanoparticles with epirubicin is created. It is discovered that attaching chemotherapy drug epirubicin to diamond nanoparticles, eliminates chemoresistant cancer stem cells. The use of nanoparticles for their sustained release improves retention in tumor tissue, reduction of systemic exposure to the drug, and the ability to bypass chemoresistance. That is studied for various agents. Researchers demonstrate the use of nanotechnology to repurpose existing chemotherapy drugs as effective agents against chemoresistant cancer stem cells. The study shows that delivery of epirubicin by nanodiamonds which resulted under normal conditions in lethal dosage of epirubicin, in becoming a safe and effective dosage. This method not only enables to combat chemoresistant cancer stem cells but may be a useful alternative for patients who cannot tolerate the toxic side effects of standard chemotherapy drugs. Moreover, the versatility of the use of nanoparticles as a drug delivery platform opens up the possibility of future applications of NDs, such as the addition of other similar drugs as well as active targeting components (e.g. antibodies or peptides against tumor cell surface proteins for targeted drug release) $(85)$.

The use of nanoparticles for their sustained release, improved retention in tumor tissue, reduction of systemic exposure to the drug, and ability to bypass chemoresistance has been studied for various agents such as epirubicin or paclitaxel.

What is more, nanodiamonds can be used as a type of non-canonical autophagy inhibitor to assist cancer therapy. Moreover, diamond nanoparticles provide a safer and efficient route for targeted cancer therapy than commercially available autophagy inhibitors because they act synergistically with anti- angiogenic drugs like Sorafenib. Due to the fact that nanodiamonds have the ability to block autophagy by effectively inducing programmed cell death in oxygen-deprived cells, with minimal perturbation on the cell viability under normal oxygen levels, the results suggest that diamond nanoparticles can block autophagic flux via a distinct mechanism from lysosomotropic agents and can be used more efficiently as a targeted reagent for cancer therapy in combination with oxygen deprivation (86).

\section{Nanodiamonds as fluorescent labels}

Diamond nanoparticles can be used as cellular markers (87) which have a large number of properties to distinguish them from the typical use of dyes or fluorescent proteins. Fluorescent nanoparticles have recently emerged as a promising theranostic probe that offers some advantages. Their special characteristics are: chemical inertia, thermal stability, low toxicity, and very stable fluorescence (88). The nanodiamonds are also able to exhibit fluorescence (red or green) and to show the ability to photoluminescence $(89,90)$.

The ability of carbon nanoparticles to fluoresce is the effect of their molecular structure. The negatively $\left(\mathrm{NV}^{-}\right)$or neutrally $\left(\mathrm{NV}^{0}\right)$ charged defects in nearby nitrogen atoms in the crystalline layer are responsible for the fluorescence of nanoparticles. These defects are defined as the colored centers, which are formed by binding the migrant of vacancy, with the impurities of nitrogen. The majority of stable defects is observed in the vicinity of the nitrogen atom and the core of nanodiamonds (91). What is more, the nitrogen is the most common contamination in the structure of diamond nanoparticles (which is formed during the process of synthesis of carbon nanoparticles (89).

NV centers can be created by irradiating nanodiamond with high-energy particles (electrons, protons, helium ions), followed by vacuum annealing at $600-800^{\circ} \mathrm{C}$. Irradiation forms vacancies in the diamond structure, and during annealing these vacancies migrate and get trapped by the nitrogen atoms that are always present in diamond $(92,93)$. The $\mathrm{NV}^{-}$center is of particular interest because it has an $S=1$ spin ground state that can be spin-polarized by optical pumping and manipulated using electron paramagnetic resonance and it has a long spin coherence time. Fluorescent NV centers in isotopically clean diamond are of particular interest for quantum computing, and NV centers in nanodiamond are also being investigated for applications in high-resolution magnetic sensing fluorescence resonance energy transfer and biomedical imaging. $\mathrm{NV}^{-}$ 
has an absorption maximum at $\sim 550 \mathrm{~nm}$ and when exposed to green-orange light, it emits bright fluorescence at $\sim 700 \mathrm{~nm}$ with a lifetime of longer than $10 \mathrm{~ns}$. Intensive red fluorescence emerges when the irradiated/annealed diamond specimen is exposed to green-yellow light. The fluorophore responsible for the observation is later identified as the negatively charged nitrogen-vacancy center, $\left(\mathrm{NV}^{-}\right)$, which exhibits a zero-phonon line (ZPL) at $637 \mathrm{~nm}$ for the electronic excitation. Its fluorescence occurs at $\sim 700 \mathrm{~nm}$ with a quantum yield close to 1 (94). Apart from the red fluorescence, a diamond can also emit green photoluminescence as well as other color variations. The development of bright photoluminescent nanodiamonds has been mostly done on materials produced by high-pressure, high-temperature synthesis (containing up to hundreds of parts per million of native substitutional nitrogen), which are then crushed down to nanosized particles. Although the concentration of the fluorescent NV defects produced by electron irradiation does not, to a first approximation, depend on the size of the nanocrystals, the fraction of $\mathrm{NV}^{-}$defects produced by the same technique decreases with decreasing size of the nanodiamond, presumably because of electron traps located at the surface. Recently, intermittent luminescence originating from $\mathrm{NV}$ centers has been observed in individual pristine 5-nm detonation nanodiamonds produced from a TNT and hexogen precursor. Stable luminescence has also recently been detected from NV centers trapped in larger (> $20 \mathrm{~nm}$ ) nanodiamonds produced from TNT and hexogen, and graphite and hexogen precursors. Various factors (such as the amount of nitrogen in the precursors and the cooling conditions) have a role in the nitrogen incorporation into the nanodiamond core and in possible in situ formation of NV centers (92).

Recently, Basso et al. have demonstrated a method in which laser ablation of graphite in liquid ambient was used to form nanodiamonds. This study presents a single-step, all-optical process where the laser ablation of a pyrolytic graphite substrate enables direct production of fluorescent nanodiamonds within nanometric range of size distribution (10-100 nm), which are embedded in a biocompatible DLC (diamondlike carbon) matrix. During the laser ablation process (performed in nitrogen atmosphere) the nitrogen is incorporated into the diamond structure. The final effect of this process are nanodiamonds with intense native photoluminescence that does not require thermal activation or additional procedures (13).

One study was conducted using diamond nanoparticles as DNA markers. In order to improve the adsorption of the diamond nanoparticles to the nucleic acid, the poly-L-lysine was attached to their surface (which gave them cationic character). In the next step, nanodiamonds with poly-L-lysine (positively charged) were surrounded by the negatively charged DNA molecule. It was the effect of electrostatic interactions. The study showed the results comparable with the effects of labeling DNA molecules by diamond nanoparticles and nanodiamond coupled to a fluorescent dye TOTO-1 (3). It was observed that the complex of nanodiamond with TOTO-1 and with DNA emits radiation (at length 545-605 nm), while the system nanoparticle-DNA emits radiation at a longer wavelength (in the range 675-685 nm). Moreover, these results showed that the fluorescence intensity of nanoparticles does not change even after modification by covalent binding of various molecules on the surface of nanodiamonds (87). Nanodiamonds conjugated to poly-L-lysine may also be used for linking various proteins such as cytochrome c. The study showed that the complex nanoparticle-cytochrome c was labeled with Alexa Fluor 488 dye and next detected by using confocal microscopy. These data proved that nanodiamonds have a lot of properties which allow assessing the physiological state of the living cells (51).

Mkandawire et al. (95) present the study, in which the diamond nanoparticles are used for labeling cellular components such as mitochondria. Especially for this purpose are used the nanoparticles which exhibit green fluorescence. Their surface is modified by attaching to antibodies against actin filaments and mitochondria. The complexes of antibody-nanoparticles are added to the HeLa cell culture and transported into the cell by dendrimers (which are used as transfection agents and agents to prevent the formation of aggregates between the nanodiamonds conjugated to antibodies). The complexes are selectively connected with mitochondria. The advantage of this method is the ability to distinguish between the fluorescence of diamond nanoparticles and the autofluorescence of the cells.

Diamond nanoparticles, which tend to have illumination, are also used for the location of growth hormone receptors on the surface of plasma membrane A549 cells. It is possible thanks to the conjugation of nanodiamond to growth hormone. The complexes which contact with the cells are able to join to receptors on the cell surface giving the light, and, on the other hand, the same unmodified nanoparticles uptake into the cells (96). Thus, the nanoparticles functionalized by an attached ligand can facilitate the location of receptors in different cells. 
A serious hindrance in the use of nanodiamonds is rapid immobilization of these nanoparticles inside endosomes after the uptake by the cells. Therefore, to eliminate this process and to halt the formation of aggregates nanoparticles, the surface of diamond nanoparticles is modified by attached lipid or micelle. The lipids connected to the nanodiamonds have no effect on the fluorescence of the diamond nanoparticles because the environment, in which are the nanodiamonds, is not affected by the emission of light from structural defects in the proximity of nitrogen atoms in particles (97). The effect of illumination of diamond nanoparticles depends on a large extent on the nanoparticles synthesis conditions that affect the formation of defects inside their structure. The luminescence of nanoparticles (size of 5-50 nm) depending on the defects on the surface, and the illumination of larger nanoparticles $(>100$ $\mathrm{nm}$ ), is the result not only of changes on the surface but also defects in the center of the structure. In practice, in order to obtain diamond nanoparticles which show fluorescence or luminescence, it is necessary to subject to prior irradiation or excitation of light using proton bombardment. Another way to excite nanoparticles is to expose them on a large dose of energy which is the result of very high temperature or glow discharge, currents of the radio or microwave frequency. It is possible to prepare nanoparticles which show a glow by surface modification. It is the result of connection fluorescent markers on the surface of nanoparticles. However, preparation of such a powder requires complicated procedure. This is due to a lengthy purification process from impurities formed during the process of synthesis and then functionalization by connecting them with fluorescence markers $(87,98,99)$.

Another example is utilizing the inherent surface chemistry of detonation nanodiamonds, an amine-functionalized gadolinium Gd (III) complex was covalently bound allowing visualization of nanodiamond particles by MR imaging. Gadolinium (Gd) is a well-known material most commonly used as an MRI contrast agent, but its contrast efficacy can be improved by conjugation with ND. The reflexivity of the Gd (III) contrast agent increased nearly 10 -fold in comparison to the free-agent upon conjugation to the nanodiamond platform (100).

Lake and Bouchard have demonstrated the first identification of subcellular protein assemblies of nanodiamonds as labels for nanoscale by using transmission electron microscopy (TEM). Their results, combined with the unique fluorescence properties and biocompatibility of nanodiamonds, represent an important step toward the use of nan- odiamonds as markers for correlated optical and electron bioimaging. The scientists describe an application for diamond nanoparticles as targeted intensity contrast labels in biological TEM using the nuclear pore complex (NPC) as a model macroassembly which is possible as a way of delivery of antibody-conjugated (Nup-98 nucleoporin) nanodiamonds to live mammalian cells using maltotriose-conjugated polypropylenimine dendrimers. As a result, the efficient localization of nanodiamonds to the intended cellular target is possible (101).

\section{Outlook}

In recent years diamond nanoparticles have been the subject of interest a possible means of targeted delivery of anticancer substances. They are extremely promising candidates for intracellular studies due to their synthesis methods, good biocompatibility and facile surface modification. As a result, their functionalization with biologically active molecules (nucleic acid, proteins, drugs) creates the possibility of their biomedical applications for drug delivery and in diagnostics. It is also necessary to be acknowledged that surface modification of nanoparticles may enable specific interactions with cell surface receptors and crossing biological barriers, in particular, the blood-brain barrier, and make it possible to deliver nanoparticles to a target site. What is more, nanodiamonds offer a promising alternative for bypassing drug efflux mechanisms. By entering the cell through endocytosis, diamond nanoparticle drug delivery can increase intracellular drug concentration and improve treatment prospects.

The efficacy of such targeted approaches in cancer therapy and, more specifically, in solid tumor targeting, has become a main point in the field. What is more, a recently published controversial meta-analysis shows (paper in Nature reviews Materials) that in preclinical models (in vivo tests), on average, only $0.7 \%$ of the injected dose (ID) of intravenously administered nanoparticles accumulates in tumors. It suggested that about 30 years of study is necessary for improving and dissolving this problem. Currently, only some basic research is conducted on animals. It is too early to predict the impact of the nanoparticles and their complexes with drugs on the human body. It is advisable to be extremely careful not to let ourselves be misled by numbers, because for patients numbers as such do not matter. It would be better if we have achieved a tumor accumulation of $7 \%$ ID instead of the now reported $0.7 \%$ ID. In the majority of cases, accumu- 
lation is largely independent of the percentage of the injected dose of drug that can be delivered to tumors, but rather it depends on a shift in the balance between off- and on-target. The main goal of research should focus on carrier-dependent drugs, and combination therapies, protocols for patient selection and procedures to enable rapid and more efficient clinical translation. It is recommended that many further studies shall be conducted in order to focus on the potential of nanoparticles for in vivo medical applications. In the future it may guarantee more effective therapy for improving patients care (102-104) and obtaining approval by the Food and Drug Administration (FDA). Currently, the FDA has approved some Nanodrugs Available for Clinical Use, including nanocrystals, micelles, proteins, dendrimers, and polymers. For the approval of diamond nanoparticles as a safe material for clinical using, more studies and tests are required (105).

The wide range of potential applications for nanoparticles will be discovered and researches will be conducted in the foreseeable future. Moreover, a better understanding of the structure and the chemical surface of nanoparticles will lead to greater control over their properties, and also will be helpful in increasing manufacturing volumes. Constant searching for new methods to obtain diamond nanoparticles as well as an increase in supply will almost certainly lead to new applications.

\section{Declaration of interest}

The authors declare no conflict of interest.

\section{REFERENCES}

1. Kelsall R.W., Hamley I.W., Geoghegan M.: Nanotechnologie, PWN, Warszawa 2009.

2. Kaur R., Badea I.: Int. J. Nanomedicine 8, 203 (2013).

3. El-Say K.M.: J. Appl. Pharm. Sci. 1, 29 (2011).

4. Colvin V.: Nat. Biotechnol. 21, 1166 (2003).

5. Simakov S.K.: Geosci. Front. 9, 1849 (2018).

6. Danilenko V.V.: Phys. Solid State 46, 595 (2004).

7. Dolmatov V.Y.: Synthesis and post-synthesis treatment of detonation nanodiamonds, in: O.A. Shenderova, D.M. Gruen Eds., pp 347-377, William Andrew, New York 2006.

8. Danilenko V.V.: Synthesizing and Sintering of Diamond by Explosion. Energoatomizdat, Moscow 2003.

9. Holt K.B.: Philos. Trans. A Math. Phys. Eng. Sci. 15, 2845 (2007).
10. Kaczorowski W., Niedzielski P.: Adva. Eng. Mater. 10, 651 (2008).

11. Mitura S.: J. Achiev. Mater. Manuf. Eng. 24, 166 (2007).

12. Solarska K., Gajewska A., Bartosz G., Mitura K.: J. Nanosci. Nanotechnol. 12, 1 (2012).

13. Basso L., Gorrini F., Cazzanelli M., Bazzanella N., Bifone A., Miotello A.: Nanoscale 10, 5738 (2018).

14. Solarska K., Gajewska A., Kaczorowski W., Bartosz G., Mitura K.: Diam. Relat. Mater. 21, 107 (2012).

15. Czerniak-Reczulska M., Niedzielski P., Balcerczyk A., Bartosz G., Karowicz-Bilińska A., Mitura K.: J. Nanosci. Nanotech. 10, 1 (2010).

16. Sumpio B.E., Riley J.T., Dardik A.: Int. J. Biochem. Cell Biol. 34, 1508 (2002).

17. Aleksenskii A.E., Baidakova M.E., Vul A. Ya., Siklikskii V.I.: Phys. Solid State 41, 668 (1999).

18. Greiner N.R., Philips D.S., Johnson J.D., Volk F.: Nature 333, 440 (1988).

19. Kruger A., Kataoka F., Ozawa M., Fujino T., Suzuki Y. et al.: Carbon 43, 1722 (2005).

20. Palosz B., Pantea C., Grzanka E., Shelmakh S., Proffen T. et al.: Diam. Relat. Mater. 15, 1813 (2006).

21. Mochalin V.N., Shenderova O., Ho D., Gogotsi Y.: Nat. Nanotechnol. 7, 11 (2012).

22. Holt K.B.: Philos. Trans. A Math. Phys. Eng. Sci. 365, 2845 (2007).

23. Krueger A., Lang D.: Adv. Funct. Mat. 22, 890 (2012).

24. Nunn N., Torelli M., McGuire G., Shenderova O.: Curr. Opin. Solid St. M. 21, 1 (2017).

25. Shenderova O.A., Shames A.I., Nunn N.A., Torelli M.D., Vlasov I., Zaitsev A.: J. Vac. Sci. Technol. B Nanotechnol. Microelectron. 37, 030802 (2019).

26. Sabirov D.S., Osawa E.: Diam. Relat. Mater. 55, 64 (2015).

27. Lim D.G., Prim R.E., Kim K.H., Kang E., Park K., Jeong S.H.: Int. J. Pharm, 514, 41 (2016).

28. Wang X., Low X.C., Hou W., Abdullah L.N., Toh T.B. et al.: ACS Nano 8, 12151 (2014).

29. Merkel T.J., DeSimone J.M.: Nanomedicine 3, 1 (2011).

30. Freitas de Freitas L., Varca G.H.C., Dos Santos Batista J.G., Benévolo Lugăo A.: Nanomaterials 8, 939 (2018).

31. Singh P., Pandit S., Mokkapati V.R.S.S., Garg A., Ravikumar V., Mijakovic I.: Int. J. Mol. Sci. 19, 1979 (2018). 
32. Stolarczyk E.U., Łaszcz M., Leś A., Kubiszewski M., Kuziak K. et al.: Nanomaterials 8, 641 (2018).

33. Stolarczyk E.U., Stolarczyk K., Łaszcz M., Kubiszewski M., Maruszak W. et al.: Eur. J. Pharm. Sci. 96, 176 (2017).

34. Du Y., Xia L., Jo A., Davis R.M., Bissel P. et al.: Bioconjug. Chem. 29, 420 (2018).

35. Krueger A.: J. Mater. Chem. 18, 1485 (2008).

36. Shenderova O.A., Ciftan Hens S.A.: Detonation Nanodiamond Particles Processing, Modification and Bioapplications, in: Ho D. Ed., pp 79-116, Nanodiamonds. Applications in Biology and Nanoscale Medicine, Springer, New York 2010.

37. Schrand A.M., Ciftan Hens S.A., Shenderova O.A.: Crit. Rev. Solid. Mater. Sci. 34, 18 (2009).

38. Aleksenskiy A., Baidakova M., Osipov V., Vul A.: The Fundamental Properties and Characteristics of Nanodiamonds, in: Ho D.Ed., pp 5577, Nanodiamonds. Applications in Biology and Nanoscale Medicine, Springer, New York 2010.

39. Burleson T., Yusuf N., Stanishevsky A.: J. Achiev. Mater. Manuf. Eng. 37, 258 (2009).

40. Osswald S., Yushin G., Mochalin V., Kucheyev S.O., Gogotsi Y.: J. Am. Chem. Soc. 128, 11635 (2006).

41. Chiganov A.S.: Phys. Solid State 46, 620 (2004).

42. Petrov I., Shenderova O., Grishko V., Grichko V., Tyler T. et al.: Diam. Relat. Mater. 16, 2098 (2007).

43. Shenderova O., Panich A.M., Moseenkov S., Hens S.C., Kuznetsov V., Vieth H.M.: J. Phys. Chem. 115, 19005 (2011).

44. Martin R., Concepcion Heydorn P., Alvaro M., Garcia H.: Chem. Mater. 21, 4505 (2009).

45. Fokin A.A., Butova E.D., Chernish L.V., Fokina N.A., Dahl J.E.P. et al.: Org. Lett. 9, 2541 (2007).

46. Jee A.Y., Lee M.: Appl. Phys. 9, 144 (2009).

47. Zhang X.Q., Lam R., Xu X., Chow E.K., Kim H.J., Ho D.: Adv. Mater.? 23, 4770 (2011).

48. Krueger A., Boedeker T.: Diam. Relat. Mater. 17, 1367 (2008).

49. Barras A., Lyskawa J., Szunerits S., Woisel P., Baoukherroub R.: Langmuir 27, 12451 (2011).

50. Shimkunas R.A., Robinson E., Lam R., Lu S., $\mathrm{Xu}$ X. et al.: Biomaterials 30, 5720 (2009).

51. Huang L.C.L., Chang H.C.: Langmuir 20, 5879 (2004).

52. Perevedentseva E., Cai P.J., Chiu Y.C., Cheng C.L.: Langmuir 27, 1085 (2011).
53. Bondar V.S., Pozdnyakova I.O., Puzyr A.P.: Phys. Solid State 46, 737 (2004).

54. Huang H., Pierstorff E., Osawa E., Ho D.: Nano. Lett. 7, 3305 (2007).

55. Kuznetsov O., Sun Y., Thaner R., Bratt A., Shenoy V. et al.: Langmuir 28, 5243 (2012).

56. Aranifard S., Shojaei A.: Diam. Relat. Mater. 89, 301 (2018).

57. Wang X., Wang Y., Chen Z.G., Shin D.M.: Cancer Res. Treat. 41, 1 (2009).

58. Haber F., Weiss J.: Proc. R. Soc. Lond. B Biol. Sci. 15, 332 (1934).

59. Martín R., Alvaro M., Herance J.R., García H.: ACS Nano 26, 65 (2010).

60. Olah G.A., Parker D.G., Yoneda N., Pelizza F.: J. Am. Chem. Soc. 98, 2245 (1976).

61. Li J., Zhu Y., Li W., Zhang X., Peng Y., Huang Q.: Biomaterials 31, 8410 (2010).

62. Kaur R., Chitanda J.M., Michel D., Maley J., Borondics F. et al.: Int. J. Nanomedicine 7, 3851 (2012).

63. Perevedentseva E., Cheng Ch.Y., Chung P.H., Tu J.S., Hsieh Y.H., Cheng Ch.L.: Nanotechnology 18, 315102 (2007).

64. Kossovsky N., Gelman A., Hnatyszyn H.J., Rajguru S., Garrell R.L. et al.: Bioconjugate Chem. 6, 507 (1995).

65. Zhang X.Q., Chen M., Lam R., Xu X., Osawa E., Ho D.: ACS Nano 3, 2609 (2009).

66. Szunerits S., Barras A., Boukherroub R.: Int. J. Environ. Res. Public Health 13, 413 (2016).

67. Bondar V.S., Puzyr A.P.: Dokl. Biochem. Biophys.373, 251 (2000).

68. Zhang Y., Rhee K. Y., Hui D., Park S-J.: Compos. Part B Eng. 143, 19 (2018).

69. Pozdnyakova N., Pastukhov A., Dudarenko M., Galkin M., Borysov A., Borisova T.: J Nanobiotechnology 31, 25 (2016).

70. Mayor S., Pagano R.E.: Nat. Rev. Mol. Cell Biol. 8, 603 (2007).

71. Zhu Y., Li W., Li Q., Li Y., Zhang X., Huang Q.: Carbon 47, 1351 (2009).

72. Fröhlich E., Samberger C., Kueznik T., Absenger M., Roblegg E. et al.: J. Toxicol. Sci. 34, 363 (2009).

73. Passagne I., Morille M., Rousset M., Pujalté I., L'azou B.: Toxicology 299, 112 (2012).

74. Solarska-Ściuk K., Gajewska A., Glińska S., Studzian M., Michlewska S. et al.: Chem. Biol. Interact. 29, 90 (2014).

75. Wang X., Low X.C., Hou W., Nurrul Abdullah L., Toh T.B. et al.: ACS Nano 8, 12151 (2014).

76. Ranganathan R., Madanmohan S., Kesavan A., Baskar G., Krishnamoorthy Y.R. et al.: Int. J. Nanomedicine 7, 1043 (2012). 
77. Jamroziak K., Młynarski W., Robak T.: Acta Haematol. Pol. 32, 131 (2001).

78. Zhu Y., Li J., Li W., Zhang Y., Yang X. et al.: Theranostics 2, 302 (2012).

79. Chow E.K., Zhang X., Chen M., Lam R., Robinson E. et al.: Sci. Transl. Med. 3, 73 (2011).

80. Shieh M.J., Hsu C.Y., Huang L.Y., Chen H.Y., Huang F.H., Lai P.S.: J Control Release 152, 418 (2011).

81. Li T.F., Xu Y.H., Li K., Wang C., Liu X. et al.: Acta Biomater. 1, 381 (2019).

82. Liu K.K., Zheng W.W., Wang C.C., Chiu Y.C., Cheng C.L. et al.: Nanotechnology 21, 1 (2010).

83. Man H.B., Kim H., Kim H.J., Robinson E., Liu W.K. et al.: Nanomedicine 10, 359 (2014).

84. Rej E., Gaebel T., Boele T., Waddington D., Reilly D.: Nat. Commun. 6, 8459 (2015).

85. Wang X., Low X.C., Hou W., Abdullah L.N., Toh T.B. et al.: ACS Nano 8, 12151 (2014).

86. Chen N., Han Y., Luo Y., Zhou Y., Hu X. et al.: Mater. Horizons. 5, 1204 (2018).

87. Fu Ch.Ch., Lee H.Y., Chen K., Lim T.S, Wu H.Y. et al.: PNAS 104, 727 (2007).

88. Vaijayanthimala V., Chang H.C.: Nanomedicine 4, 47 (2009).

89. Barnard A.S.: Analyst 134, 1751 (2009).

90. Yu S.J., Kang M.W., Chang H.Ch., Chen K.M., Yu Y.Ch.: J. Am. Chem. Soc. 127, 17604 (2005).

91. Bradac C., Gaebel T., Naidoo N., Rabaeu J.R., Barnard A.S.: Nano Lett. 9, 3555 (2009).

92. Chang H.Ch.: Development and Use of Fluorescent Nanodiamonds as Cellular MarkersNano- diamonds, Applications in Biology and Nanoscale Medicine, Ed., D. Ho, Springer, 2009.

93. Georgakilas V., Perman J.A., Tucek J., Zboril R.: Chem. Rev. 115, 4744 (2015).

94. Hsiao W.W.W., Hui Y.Y., Tsai P.Ch., Chang H.Ch.: Acc. Chem. Res. 49, 400 (2016).

95. Mkandawire M., Pohl A., Guberewich T., Lapina V., Appelhans D. et al.: J. Biophotonics 2, 596 (2009).

96. Cheng C.Y., Perevedentseva E., Tu J.S., Chung P.H., Cheng C.L. et al.: Appl. Phys. Lett. 90, 163903 (2007).

97. Hui Y.Y., Zhang B., Chang Y.C., Chang C.C., Chang H.C. et al.: Opt. Express 18, 5896 (2010).

98. Schrand A.M., Lin J.B., Hens S.C., Hussain S.M.: Nanoscale 3, 435 (2011).

99. Lien Z.Y., Hsu T.C., Liu K.K., Liao W.S., Hwang K.C., Chao J.I.: Biomaterials 33, 6172 (2012).

100. Manus L.M., Mastarone D.J., Waters E.A., Zhang X.Q., Schultz-Sikma E.A. et al.: Nano. Lett. 10, 484 (2010).

101. Lake M.P., Bouchard L-S.: PLoS One 21, e0179295 (2017).

102. Lammers T., Kiessling F., Ashford M., Hennink W., Crommelin D., Storm G.: Nat. Rev. Mater. 1, 16069 (2016).

103. Wilhelm S., Tavares A.J., Dai Q., Ohta S., Audet J. et al.: Nat. Rev. Mater. 1, 16014 (2016).

104. Torrice M.: ACS Cent. Sci. 2, 434 (2016).

105. Ventola C.L.: P.T. 42, 742 (2017).

Received: 6.02.2019 